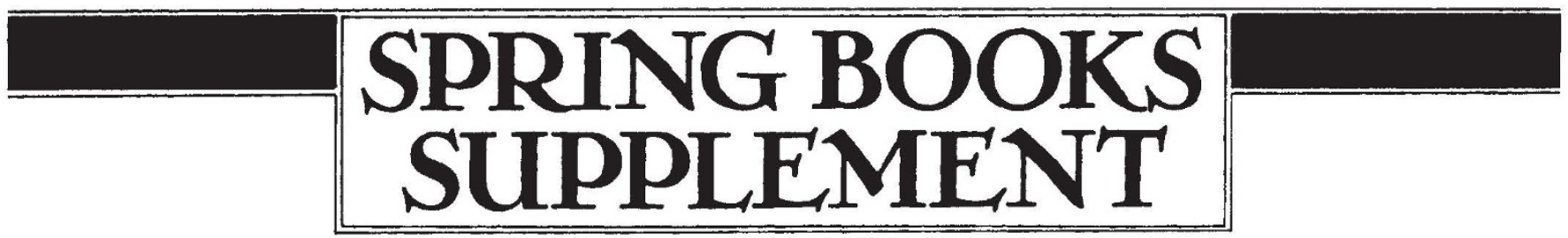

\title{
Reviewers without pride or prejudice
}

What are book reviews for? The question is not entirely trivial. The pages that follow are filled with the comments of a great many serious people who have taken the trouble to read some book or books, to reflect on the contents thereof and then to tell the rest of the world what they think of them. Why, it will be asked, should they bother? Why should an army of people who are (or who should be) disinterested take this trouble for the sake of others the people who lie somewhere between those who would certainly buy the book concerned, perhaps because it represents a special interest of theirs, and those who would not willingly be seen in public reading the document concerned, and who would not wish to do so in private either? Pecuniary reward is not the explanation. The simple answer is that book reviewers pursue one of the most honourable of intellectual crafts. The ideal reviewer is a self-effacing person - the kind of person who is sufficiently knowledgeable to have written the book he is charged with off his own bat, who might well indeed have done so if he were not so busy, but who has nevertheless been willing to quarry time from a busy timetable to inform and instruct potential readers of a new apparition in the literature. The scientific community, any intellectual community, has reason to be grateful to reviewers.

But why are books so especially deserving of attention? What is it about a pair of hard covers that gives a book precedence over, say, an article in a scientific or other journal? Rarity is only part of the explanation. Some journals, Nature among them, do indeed try to pick out and draw to the attention of their readers particularly interesting articles that appear in the ordinary course of communication. The volume of the scientific literature is of course too great for this task to be attempted (or at least accomplished) systematically. There is, however, another sense in which a book commands (and deserves) to be dealt with differently from the report of some piece of research, whatever the excitement engendered by the results. For a book, or at least a good book, is necessarily a somewhat personal declaration. So much can be told from a comparison of the style of run-of-themill scientific articles and books by the same authors. The authors of articles run to the passive, and to opening sentences such as "There is now much evidence to suggest that ...". The authors of books write in a different frame of mind. They are, from time to time, prepared to utter sentences beginning "I believe that...". More than this, books differ from articles in the journals in their objectives. Both kinds of contributions to the literature have a beginning and a middle, but only of books (or good books) is it required that there should also be a conclusion of some weight and finality. The authors of articles in the journals are allowed to finish with a statement to the effect that they are entirely at a loss to understand the observations they report and to declare that they will do their best, in competition with those who are stimulated by reading their contribution to the literature, to find out. Would-be book authors, by contrast, must (or should) know before they put pen to paper what case they seek to make. (Publishers who make books by stringing together a miscellaneous collection of articles, or collections of papers given at some symposium, must by the same token appreciate that these are comparatively dull, not much like books.)

There is another crucial respect in a which a book differs from some other contribution to the literature. Although some books may only be ten times longer than, say, some journal articles, the difference of scale is a quantitative difference big enough to imply a qualitative difference. As the world knows, book authors are repeatedly perplexed to know whether the point they are about to make in chapter umpteen has already been made in chapter one. Put simply, those who set out to write books, and actually finish them, command a certain respect, even from those who may disagree with the conclusions.

Good reviewers appreciate these truths, and are (or should be) compassionate people. If somebody writes a routine account of, say, the inorganic chemistry of selenium, and if the arrangement of the chapters is not precisely what the reviewer would have chosen, that does not amount to an excuse for a fierce attack on the author and his good sense and a warning that students everywhere should avoid the book like the plague. In such fields it is well known that the unkindest course a reviewer can follow is to say nothing at all: then potential purchasers will have to learn of the book by chance, while the book's publishers will be at their wits' end, seeking other ways of putting news of the book's appearance into circulation. In the last resort, after all, the reviewer's task is to tell potential readers what a book seeks to accomplish and to say whether the author has done what he set out to do. Part of the book reviewer's licence is that he may, in passing, add a few reflections of his own on the good sense of the author's goal. So most book reviews should be essays in sympathetic understanding, marked sometimes with sorrow, rarely with anger. And so they usually are.

There are, however, exceptions to this benign rule. For the class of well-conceived books, each with its own sharp conclusion, is bound to include many whose conclusions are at once mistaken, even mischievous, but also likely to be persuasive. This is why the craft of book reviewing frequently runs to polemic. This is why $\mathrm{H}$. J. Eysenck's The Causes and Effects of Smoking (Temple Smith, 1980), or Samuel Epstein's The Politics of Cancer (see Nature 284,297 ; 1980) persuaded reviewers to soak their typewriter ribbons in vitriol. The arguments, right or wrong (and probably wrong, or at least incomplete), are such a challenge to accepted doctrine and at the same time so self-consciously challenging that it is helpful to readers to know the strength of opinion on the other side. Polemic is therefore part (but ideally a small part) of book review columns. Professor Dorothy Hodgkin's review of Maurice Goldsmith's book on J. D. Bernal (Sage, Hutchinson, 1980; see Nature 289, 99; 1981) is more puzzling. Goldsmith set out to write a biography of one of his heroes, and was savaged for his pains by another hero-worshipper, his reviewer. No doubt the book is, as Professor Hodgkin says, "confused and inaccurate". It is also, however, a good book in the sense of being a good read and also (for a hero-worshipper) honest in that it deals with the warts as well as the achievements - sexual proclivities, ambivalence about Lysenko and all that. Maybe Goldsmith's book is "not the book that is needed about Bernal", but it is the only book we have. On this occasion, polemic seems to have been misplaced. In general, the truth about books is that they are milestones for somebody certainly the author and the publisher - and that there are some occasions on which even bad books are better than no books. Moreover, books differ from other contributions to the literature of scholarship in the diversity of their readership. Their influence on students is important. And books - or good books - can survive from one decade to another. 